ISSN: 0210-1696

DOI: https://doi.org/10.14201/scero20215246786

\title{
EL FUNDAMENTO FILOSÓFICO-JURÍDICO \\ DE LA DIGNIDAD DE LAS PERSONAS QUE SE ENCUENTRAN EN SITUACIÓN DE DISCRIMINACIÓN A CAUSA DE UN BAJO DESEMPEÑO FUNCIONAL: UNA MIRADA DESDE LA AXIOLOGÍA DE MAX SCHELER
}

\section{The Philosophical-Legal Basis of the Dignity of People who are in a Situation of Discrimination Due to Low Functional Performance: a View from Max Scheler's Axiology}

Ángel Damián Román OrTiz

Universidad de Murcia. Departamento de Didáctica y Organización Escolar. Facultad de Educación. Equipo de Investigación DIDE (Diversidad Funcional y Derechos Humanos)

Jesús Molina SAORín

Universidad de Murcia. Departamento de Didáctica y Organización Escolar. Facultad de Educación. Equipo de Investigación DIDE (Diversidad Funcional y Derechos Humanos) jesusmol@um.es

\section{Yonatan DíAz SANTA MARía}

Universidad de Murcia. Departamento de Didáctica y Organización Escolar. Facultad de Educación. Equipo de Investigación DIDE (Diversidad Funcional y Derechos Humanos)

José María Álvarez Martínez-Iglesias

Universidad de Murcia. Departamento de Didáctica y Organización Escolar. Facultad de Educación. Equipo de Investigación DIDE (Diversidad Funcional y Derechos Humanos) 
RESUMEN: Históricamente, la terminología empleada para denominar a las personas que tienen un bajo desempeño funcional siempre ha ido acompañada de esos lenguajes de la negación que -como si de un hecho imperecedero se tratase-, relacionan persistentemente las capacidades de estas personas con su aparente incapacidad para obrar, impidiendo (para una inmensa mayoría, y desde un punto de vista jurídico) el ejercicio pleno de sus derechos. Igualmente, el transcurso conceptual que -a lo largo de la historia- ha ido persiguiendo a la figura de las personas con bajo desempeño funcional confirma ese vapuleo de constructos que -en la actualidad, y sin ningún género de dudas-conduce a la construcción de la mayoría de las situaciones de discriminación por motivo de desempeño funcional. Bajo esta óptica, la idea central de este artículo pretende conceptualizar la dignidad del ser humano desde el concepto filosófico de persona utilizado por Max Scheler (1874-1928), y abstraído de esa perspectiva biomédica de la -mal llamada- discapacidad, y siempre vinculando esa innegociable condición humana con la capacidad de amar y ser amado. Como trasfondo epistemológico, se exponen -gravitando- los fundamentos cognoscentes de la teoría de los valores y que responden a esa pregunta obligada (¿quién es la persona humana?) y cuya respuesta se acomete desde la distinción de la noción de persona y la noción de yo propuesta por este filósofo alemán.

Palabras Clave: derecho; discapacidad; bajo desempeño funcional; dignidad; diversidad funcional; axiología; Max Scheler.

ABSTRACT: Historically, the terminology used to refer to people who have low functional performance has always been accompanied by those languages of denial that -as if it were an imperishable fact-persistently relate the capacities of these people with their apparent inability to act, preventing (for a vast majority, and from a legal point of view) the full exercise of their rights. Likewise, the conceptual course that -throughout history- has been pursuing the figure of people with low functional performance confirms that beating up of constructs that -at present, and without any doubt- leads to the construction of most situations of discrimination based on functional performance. From this perspective, the central idea of this article aims to conceptualize the dignity of the human being from the philosophical concept of the person used by Max Scheler (18741928), and abstracted from that biomedical perspective of the -misnamed-disability, and always linking that non-negotiable human condition with the ability to love and be loved. As an epistemological background, the cognitive foundations of the theory of values are exposed -gravitating- and that respond to that obligatory question (who is the human person?) and whose answer is undertaken from the distinction of the notion of person and the notion of me proposed by this German philosopher.

KEYWORDS: right; disability; low functional performance; dignity; functional diversity; axiology; Max Scheler's.

\section{Introducción}

L PENSAMIENTO POSMODERNo ha puesto de relieve las dificultades que plantea el
concepto moderno de dignidad basado en la razón; sin duda, estas dificultades
pueden hacerse extensivas también al ámbito filosófico-jurídico de la discapa-

Ediciones Universidad de Salamanca / CC BY-NC-ND

Siglo Cero, vol. 52 (4), 2021, octubre-diciembre, pp. 67-86 
cidad y al fundamento de la dignidad de las personas con bajo desempeño funcional. La idea central de este trabajo es conceptualizar la dignidad humana desde un pensamiento filosófico de persona, caracterizado no tanto en su capacidad intelectual -o física- (es decir, no tanto en la racionalidad ilustrada) como en su indudable condición humana frente a la potencialidad de amar y ser amadas que comparten todas las personas que históricamente han sido discriminadas en virtud de un menor desempeño funcional (a nivel intelectual o motriz, fundamentalmente). Igualmente, se discute al respecto de algunas de las dificultades vividas por las personas con bajo desempeño funcional, todo ello desde una concepción filosófica de la persona basada en la axiología que propone Max Scheler. Esta perspectiva permitiría enriquecer el esquema ínsito en el modo habitual de concebir la diversidad funcional en el ámbito jurídico, en virtud del cual se suple la capacidad intelectiva de la persona mediante diversos sistemas (tutela y curatela), poniendo el acento en el amor como principal resorte del entender y del querer posterior. Este cambio de perspectiva se muestra así más acorde con el modelo social (próximo a ese pensamiento en base al cual las personas - mal llamadas- con discapacidad pasan a concebirse como personas en situación de discapacidad, comprendiendo que la discapacidad es conexa a las barreras impuestas socialmente y no es, tal y como se venía defendiendo, un elemento de la propia persona) y también con lo establecido por la Convención Internacional de la ONU sobre los Derechos de Personas que se encuentran en situación de discriminación por su desempeño funcional (López, 2019). Y para despejar todo el marasmo de terminología y conceptualizaciones perversas arrastradas desde el pasado, y comprender mucho mejor las implicaciones que tiene el uso de la semántica en este ámbito, se ha seguido la línea discursiva que propone Molina $(2017,2020)$, con el deseo de aproximar al lector al buen uso de las nomenclaturas planteadas (discapacidad, diversidad funcional, situación de discapacidad y desempeño funcional). En efecto, con la finalidad de alcanzar la mayor coherencia expositiva, en los siguientes apartados se lleva a cabo una diferenciación de diferentes nomenclaturas utilizadas - hasta el momento- para denominar a quienes tienen un bajo desempeño funcional.

En este sentido, cuando se habla de diversidad funcional se hace referencia a una condición del desempeño humano y que, por lo tanto, afecta a todas las personas. Cada persona tiene un desempeño funcional en todas y cada una de las capacidades, habilidades o destrezas que el ser humano comparte (fuerza, flexibilidad, resistencia, inteligencia, velocidad, cálculo, abstracción, dibujo...), y en virtud de tales capacidades resulta -también- evidente que todas y cada una de las personas van a tener un desempeño funcional (Molina, 2017) en aquellas habilidades que -con toda seguridad-se distribuye entre el máximo desempeño conocido (por ejemplo, tratándose de una habilidad deportiva, correspondería a una marca olímpica) hasta -evidentemente- el desempeño cero (por ausencia de la capacidad que envuelve a tal habilidad). Esto es lo que sucede naturalmente: esto es lo que debiera ser admitido socialmente; sin embargo (y en palabras de Molina, 2020), sucede que ni se acepta la diversidad ni tampoco se admite la heterogeneidad, y por ello la no aceptación de ese bajo desempeño funcional (que se desenvuelve en ese intervalo de logro que va desde la ausencia de capacidad hasta la capacidad máxima conocida) acaba generando situaciones de 
discriminación hacia aquellos que acaban teniendo menor desempeño funcional en determinadas capacidades, de ahí que desde ese modelo (actualizado) de los derechos humanos -que aquí se pone en valor-podamos afirmar que ya no es posible considerar que es la persona la que tiene una discapacidad (como se venía diciendo -infelizmente-) ni tampoco los eufemismos que se han ido acuñando (persona con diversidad funcional, persona diferente, persona con características especiales... -y otra suerte de neologismos que tan solo son tautologías del pasado-), sino que con base en la óptica que concede la CDPD de la ONU, 2006 (en la que se definen los ajustes razonables y se establece la relación entre las barreras -como variables exógenas al ser humano- y la propia persona -variable endógena-), nos hace considerar que el resultado de desviar la atención de nuestra mirada sobre ese concepto de diversidad funcional supone condenar a buena parte de la población a la tiranía de una situación de discriminación de la que no pueden escapar, al tiempo que se priva al resto de la población del goce de disfrutar, aprender y convivir con estas personas a quienes -históricamente- siempre han secuestrado del ejercicio de sus derechos. Precisamente por ello, cabe afirmar que las personas con bajo desempeño funcional son el mejor ejemplo posible para fundamentar la propia condición humana -esencial- del derecho, desde la cual, más allá de elementos accidentales o circunstanciales, la dignidad permanece intacta.

\section{El concepto de discapacidad: un largo recorrido hasta nuestros días}

El concepto de discapacidad ha ido evolucionando a lo largo del tiempo como resultado de una construcción sociocultural; desde el punto de vista semántico, discapacidad se define -actualmente- como "cualidad de discapacitado", siendo "discapacitado" un adjetivo que indica que una persona tiene impedida o entorpecida alguna de las actividades cotidianas -consideradas normales- por alteración de sus funciones intelectuales o físicas. La diferencia radica, precisamente, en la definición del propio concepto que se define en el art. ${ }^{\circ} 1$ de la Convención Internacional sobre los Derechos de las Personas que se encuentran en situación de Discapacidad (CDPD, 2006); concepto que supone que la discapacidad encierra -en sí misma- "un componente evolutivo que va a depender tanto de las condiciones de la persona, como también de la interacción de dichas condiciones con otras múltiples variables de su entorno físico, social, económico, etc.” (Molina, 2017, p. 2). La incorporación del modelo de derechos humanos y su reconocimiento en la Convención se traduce en que ya "no debemos adoptar una actitud paternalista ni pretender aliviar los males a las personas que se encuentran en situación de discapacidad" (Molina, 2017, p. 2), sino que el punto de vista se centra ahora en tratar de poner todos los medios para que puedan ejercer sus derechos y queden plenamente incorporadas en la sociedad.

Las situaciones de discapacidad no pueden considerarse como enfermedades, toda vez que incluso para aquellos casos en los que tal situación esté basada en una enfermedad, se utiliza la ciencia y la medicina para abordarla. Desde este planteamiento queda claro, por lo tanto, que la propia discapacidad es algo que crea la sociedad, y precisamente la CDPD incorpora un concepto tamizador cuando -al hablar de per- 
sonas con discapacidad en el art. ${ }^{\circ}$ 1.2.- se indica que se "incluye a aquellas que tengan deficiencias físicas, mentales, intelectuales o sensoriales a largo plazo, que al interactuar con diversas barreras puedan impedir su participación plena y efectiva en la sociedad en igualdad de condiciones que las demás” (Molina, 2017, pp. 13-14). Desde el denominado modelo de los derechos humanos (Braslavsky, 2006; Campoy, 2017; Foschiani, 2017), se entiende la discapacidad como el resultado de la exclusión (de la sociedad) y de una falta de respeto (de dicha sociedad) a la diversidad humana (precisamente ante la presencia de un bajo desempeño funcional), siendo lo más importante entender que el objetivo central de la CDPD es "garantizar y reconocer la dignidad de la persona en situación de discapacidad, asegurando el ejercicio de sus derechos" (art. ${ }^{\circ}$ 1). Desde este punto de vista, el papel de las políticas y legislaciones habría de ser el de promover, proteger y asegurar el ejercicio de los derechos de los ciudadanos y no limitarlos por el hecho de que exista un bajo desempeño funcional (evitando también la protección excesiva). Infelizmente, en la actualidad todavía no podemos afirmar que las políticas públicas y las legislaciones nacionales estén alineadas con aquellos preceptos recogidos en la Convención; "todavía hoy asistimos a limitaciones de derechos que ponen de relieve el insignificante grado de compromiso de las políticas públicas en esa persecución de un nivel cero de discriminación” (Molina, 2017, p. 29).

Desde una visión ortodoxa de la discapacidad (generadora de muchas de las prácticas que existen alrededor de la misma -y también presente en el imaginario social-), tradicionalmente se ha partido del entendimiento de que la discapacidad tiene que ver con la fisiología de la persona, con una cuestión de naturaleza estrictamente individual en la cual el contexto no genera ningún tipo de influencia. Desde esa óptica, lo que se ha ido proponiendo ha sido -precisamente- el tratamiento ante el problema fisiológico, y para ello se ha puesto a disposición la ciencia médica junto con toda una serie de estrategias rehabilitadoras o terapéuticas. Frente a esta posición surgió el denominado modelo social; se trata de un ámbito de investigación sociológico gestado desde el escenario anglosajón en la década de 1980, en virtud del cual se plantea que la discapacidad no es un fenómeno médico sino un fenómeno social. Bajo este paradigma se defiende que, a pesar de que el sustrato fisiológico es incuestionable, el hecho de que se produzca una manifestación social en la comprensión de la diversidad funcional cuyo resultado sea la marginación y la exclusión, tal construcción no tiene que ver con ese déficit fisiológico (Molina, 2017), sino con todas las estructuras sociales y contextos de convivencia que desarrollan su existencia en sentido amplio (contextos de convivencia desarrollados por y pensados para personas que no están en situación de discriminación por motivo de bajo desempeño funcional, y que no toman en consideración otras circunstancias humanas y necesidades específicas que -ciertamenteexisten). Por lo tanto, a la hora de contextualizar la construcción de la discapacidad no es tan importante el aspecto fisiológico, sino los entornos y contextos de la convivencia (aspectos materiales, simbólicos y afectivos). Son precisamente esos entornos los que hacen que se produzcan aquellas condiciones que-efectivamente- provocan que ciertas personas estén condenadas a procesos de marginación, discriminación y exclusión social. Desde esta perspectiva crítica, la normativa jurídica (el marco legislativo) también forma parte de ese contexto, motivo por el cual parece necesario comprobar 
el efecto que dicho entorno normativo genera en la experiencia real y concreta de las personas que están siendo discriminadas en virtud de su desempeño funcional. A nivel nacional, es posible afirmar que la normativa existente prácticamente no tiene efectos reales en la experiencia de las personas que se encuentran en situación de discapacidad, tal y como se desprende de los resultados del proyecto europeo financiado por el Ministerio de Ciencia e Innovación y desarrollado por el equipo del profesor Ferreira (Seguimiento cualitativo de jóvenes en situación de discapacidad en estados europeos: el caso español-Quali-TYDES-SP; 2010-2013). Con respecto a la normativa falta una aplicabilidad efectiva, y también una repercusión real en la experiencia de las personas que se encuentran en situación de discapacidad. Las evidencias que se recogen en este proyecto reflejan el absoluto desconocimiento - por parte de las propias personas- de los derechos que les amparan, mostrando total sumisión en todas las estructuras sociales, materiales y simbólicas que son -precisamente- las que acaban condenándoles a la marginación y exclusión social. Si asumimos que -efectivamente- puedan ser las estructuras las que condicionan la existencia, y asumimos también todas las evidencias empíricas que demuestran esa condición estructural de marginación y exclusión, la pregunta más simple sería la siguiente: ¿por qué sucede esto? Y es precisamente ahí donde emerge la necesidad de iniciar un trabajo de carácter cualitativo; es necesario buscar un marco teórico de referencia que permita resituar el objeto de estudio desde un punto de vista diferente (en su dimensión social). En este sentido, el primer paso coherente podría ser apropiarnos de aquello que desde el modelo social se dejó de lado: lo fisiológico. El cuerpo no es solo una mera materialidad (Stilker, 2017), algo inerte (un sustrato ajeno a dinámicas de carácter simbólico), sino que lo corpóreo es una construcción social y se construye en espacios convivenciales y mediante discursos simbólicos (Molina, 2017). A este respecto, Bourdieu (1988) ya planteó su noción de habitus entendida como la relación entre lo objetivo (posición en la estructura social) y lo subjetivo (interiorización de ese mundo objetivo). Es decir, desde la posición de agentes sociales, para alcanzar la eficiencia no es necesario ser grandes pensadores en la mayoría de las situaciones de la vida cotidiana; y la fundamentación para esta hipótesis la sitúa en la familiarización, entendida como capacidad práctica, física y mental por la cual nuestro cuerpo interioriza y ejecuta eficientemente toda una serie de prácticas cotidianas sin necesidad de requerir una exigencia de pensamiento (por ejemplo, la práctica permite al conductor experimentado manejar su vehículo al tiempo que mantener una conversación, prestar atención al contenido de la radio, etc.). Una pregunta derivada de este razonamiento sería: ¿habrá algo relevante -y de esta índole- en la experiencia de las personas con bajo desempeño funcional que permita vislumbrar las razones que pueda haber detrás de todas esas evidencias empíricas? Todo hace pensar que sí, que efectivamente existe un habitus de la discapacidad, lo cual implica una determinada conformación de la corporalidad de las personas con bajo desempeño funcional que, a su vez -y de partida-, es algo muy evidente (porque lo que tradicionalmente se hace con el cuerpo está muy determinado por la diagnosis médica, la rehabilitación, etc.). Sin embargo, no debemos caer en el error -en ocasiones frecuente- de significar solo la especificidad de aquello que estamos tratando (lo corpóreo) y perder de vista que -tal vez- esa especificidad está conformada por algo 
más genérico y que nos afecta a todos, lo que nos retrotrae a los planteamientos de Michael Foucault (1926-1984) cuando afirmaba que desde la modernidad se pone en marcha una estrategia (propiciada por los poderes políticos) de conformación y adoctrinamiento de los cuerpos de los ciudadanos.

Precisamente, el aparato eficaz para lograr esa disciplina generalizada lo constituye el sistema educativo; hemos asumido (toda vez que forma parte del ideario de la ilustración de la modernidad - una vez que se universaliza el acceso a la institución educativa) - que la escuela es algo que sirve para darnos un futuro posterior (Teresinha, 1998). Es decir, supuestamente la escuela posibilita adquirir conocimientos que nos permitan obtener cualificaciones profesionales, y en virtud de las cuales accederemos al mercado laboral, teniendo más oportunidades laborales que quienes no transitaron por el sistema escolar. Siguiendo a Bourdieu, esto sería una absoluta falsedad, precisamente porque el aparato escolar es un dispositivo de selección y exclusión social en términos culturales, diseñado para obligar a todo el mundo a pasar por un único -y homogéneo-filtro, el cual implica una determinada cultura erudita que solo es potestad de una minoría (entre la que se encuentran sus diseñadores). Pero esta es solo una de las dimensiones no explicitadas del aparato escolar; sucede que -además- las materias que se imparten se organizan en áreas específicas previamente seleccionadas (matemáticas, geografía, etc.) y, sin embargo, no se abordan otros ámbitos muy útiles en determinados contextos (agrícolas, ganaderos o pesqueros), como la percepción sensorial ante los cambios meteorológicos, la orientación geográfica y temporal, etc. Por otra parte, y durante un período obligado de -al menos- una década, estamos sistemáticamente obligados a ejecutar ciertos rituales corporales, de tal suerte que adquirir conocimiento en el aula adecuadamente es sinónimo de permanecer sentado y en silencio; en el caso de existir una cátedra, es el profesor el único que la ocupa dirigiéndose a sus alumnos desde una proyección cráneo-caudal que -corporalmente- establece una nítida jerarquía (durante muchos años ha existido en lo más alto de la pared un crucifijo -como elemento más elevado y más próximo del cielo-, bajo este un cuadro con la figura del monarca, bajo dicho cuadro el espacio ocupado por el profesor, a sus pies la cátedra y bajo esta el alumnado: este ha sido el orden del amor incuestionable-Molina, 2017-).

Evidentemente, si bien la experiencia vital de una persona fluctúa en función de múltiples variables (entre las cuales se encuentran el contexto económico y cultural), pueden llegar a ser muy diferentes las experiencias mantenidas por una persona en función de que su lugar de nacimiento o residencia sea un hábitat periférico o central, como diferente será también su experiencia vital en función de si la situación de discriminación vivida la ha conocido desde que tiene recuerdo o ha sido sobrevenida. En este sentido, cuando durante el tránsito de la vida de una persona que sobreviene en situación de discapacidad, esta comporta dos experiencias vitales: una en la que no existía esa situación y otra en la que dicha situación de exclusión aparece en escena. Desde el año 1929 en el que se inician los llamados estudios de eficacia, y hasta finales de la década de 1960, quedó demostrado que -efectivamente- para aquellos alumnos con (las mal llamadas) necesidades educativas especiales que tuvieron un trasunto educativo inclusivo pasando por una escolaridad obligatoria en centros ordinarios, 
efectivamente, quedó acreditada la mejora en su eficacia, rendimiento, autocontrol y autoestima, motivo por el cual se concluyó que no debía producirse la escolarización en centros de educación especial:

Se demostró -entonces- que desde la educación inclusiva (debidamente aplicada, con sus recursos, apoyos, formación de profesorado, etc.) los alumnos llegaban a aprender -como mínimo- lo mismo que hubiesen aprendido en un centro de educación especial, si bien todas las variables anteriormente citadas (eficacia, rendimiento, autocontrol y autoestima) se veían mejoradas en el entorno inclusivo (Molina, 2017, p. 34).

\section{El concepto de diversidad funcional: un hecho consustancial al ser humano}

La diversidad es inherente al ser humano, y en virtud de ella todos habremos de tener un desempeño funcional heterogéneo ( $\mathrm{y}$ en virtud del cual se comprende que el foco de atención ha de colocarse no en las limitaciones, sino en las posibilidades funcionales de cada persona). En defensa de la diversidad del ser humano, en los últimos años se ha acuñado una nueva conceptualización con objeto de evitar que se siga concentrando el foco de atención en la propia persona, naciendo así el constructo "diversidad funcional”. Bajo este nuevo concepto marco, sus ideólogos propusieron acabar con el uso de la expresión "personas con discapacidad" para pasar a denominarlas "personas con diversidad funcional". No obstante, y con base en nuestros estudios y resultados de investigación,

si bien es innegable el importante éxito que ha supuesto esta nueva conceptualización al desarrollo intelectual en esta materia (en la medida en que ha permitido denunciar tanto el uso inaceptable de esa sustantivación perversa de un adjetivo, como también la imperdonable invisibilización de las propias personas al desaparecerlas en el constructo), no es menos cierto que su incorporación precipitada y lejana de reflexiones epistemológicas de mayor calado (tanto científicas como también filosóficas o semánticas) tan solo ha supuesto un cambio estético, un formalismo semántico, un eufemismo resultante de aplicar un fino maquillaje (Álvarez, Díaz y Molina, 2021 -en prensa-)

en la medida en que se ha pasado de hablar de "personas con discapacidad" para hablar de "personas con diversidad funcional". Pero -en el fondo- con ello nos seguimos refiriendo a lo mismo, seguimos pensando en las mismas personas: al usar este constructo ("personas con diversidad funcional") se piensa tan solo en unas personas, pero no en el resto. Esta no es nuestra conceptualización (pensamos que su uso también contribuye a perpetuar un serio error). Precisamente con objeto de cambiar este nefasto marco epistemológico que hemos heredado, y a partir del cual se han establecido los ritmos y tiempos en la conceptualización de las diferencias humanas, que se hace tan necesaria la pertinencia de ofrecer un enfoque que -realmente- concentre la atención en aquello que resulta incontrovertible: que la diversidad es una cualidad tan consustancial como inherente al hecho humano. Y si entendemos que lo normal es la diversidad, entenderemos -por lo tanto- que lo normal es la diferencia; y si somos 
capaces de despojar de ideologías la comprensión de la diferencia (en el sentido estricto de no asociar valores negativos a las diferencias humanas -sean de tipo motriz, intelectual, sensorial, etc.-), solo en ese caso estaremos entonces en condiciones de pasar a entender el concepto de diversidad funcional. A lo largo del tiempo, el concepto de diversidad ha ido experimentando un cambio significativo evidenciando -de este modo- que la existencia de diferencias individuales es un hecho consustancial a la condición humana (Álvarez et al., 2021).

En España, llevamos más de medio siglo con políticas públicas en pro de los beneficios de las personas - mal llamadas-con discapacidad. Precisamente, las propias personas consideradas como activistas de un nuevo movimiento social (autores como Javier Romañach, Soledad Arnau, Giampiero Aristide, etcétera) no quieren que se continúe hablando de discapacidad, pasando a hablar de diversidad funcional, precisamente porque entienden que dentro de la diversidad funcional estamos todos los seres humanos; es decir, todos tenemos diferencias en la potencialidad de nuestras capacidades: unos tienen más capacidad para saltar y otros menos; unos más capacidad para ver y otros menos -o incluso ninguna-; unos son más altos, otros más delgados, unos con más fuerza, otros con mayor memoria, etc. Y, coherentemente, esta diversidad habríamos de contemplarla al abrigo de la normalidad: lo normal es la diversidad. Sin embargo, sucede que cuando la propia persona percibe que el resto de su hábitat le está considerando como un ser anormal -por su condición- es cuando hace acto de presencia la discapacidad, momento en el que asociamos una situación de discapacidad a partir de otra previa de naturaleza discriminatoria (Molina, 2017). Precisamente por esto es concebible que una persona se perciba a sí misma sin discapacidad. Fruto de la interacción humana, se produce aquella familiar situación que aparece cuando algunas personas ven a otras y lo primero que aprecian no es a la persona -por encima de cualquier otro rasgo-, sino la deficiencia (que tiene un síndrome, que no tiene un brazo, que lleva un bastón, etc.); y cuando esto sucede -como el título de la obra de Molina (2017) - la discapacidad empieza en tu mirada: la mayor parálisis cerebral está en los ojos del que mira, que no es capaz de advertir lo que está más allá de unos rasgos que bien podrían ser meramente estéticos o estructurales, pero que en absoluto sustituyen lo esencial (la persona), al tiempo que todo ese artefacto representado se decodifica igualmente como algo anormal (desde el punto de vista estadístico, social, etc.). Precisamente desde el punto de vista estadístico, si bien 1000 millones de personas en situación de discapacidad representan el $15 \%$ de la población mundial, no parece que pueda ser una pequeña cifra si la comparamos con la población total europea (que es de tan solo 700 millones de personas). Es decir, que pese a ser tan solo un $15 \%$ de la población mundial, si quisieran pasar un día en los hogares de Europa (y ceder los europeos nuestras viviendas por un día), faltarían hogares en los que hospedarles. Por lo tanto, aunque se trate de un porcentaje aparentemente pequeño (siempre analizado en términos relativos), necesariamente hemos de aprender a ver ese $15 \%$ como algo normal: una minoría de personas tiene muy malas condiciones de vida porque una amplísima mayoría no hace lo necesario por facilitar aquellas condiciones sociales que ayudarían -sobremanera- a la mejora de la calidad de vida de los primeros (Molina, 2017). Si entendemos que las políticas públicas orientadas hacia la 
mejora de la calidad de vida de las personas en situación de discapacidad son necesarias, porque es necesario educar y reeducar a la sociedad al respecto de la diversidad funcional humana, seguramente caeríamos en la cuenta de lo rentable que resultaría aprovechar el aparato escolar para este propósito, porque si desde pequeños todos los ciudadanos (niños y niñas) tuviesen la oportunidad de convivir cotidianamente con otros semejantes con lesión cerebral, ceguera, sordera, síndrome de Down, acondroplasia, síndrome de Williams, etc., con toda seguridad crecerían aprendiendo que lo normal es la diversidad, que lo normal es que haya personas con síndrome de Turner, que lo normal es que el sordo no oiga, que lo normal es que el niño ciego necesite más tiempo para leer -idéntico texto- que otro niño vidente, etcétera;

y todo ello se traducirá (como ya sucede en otros países nórdicos) en una absoluta asunción y sensibilidad -que algunos llamarían de sentido común y educación exquisitaque nos permita entender que no aparcar en determinadas zonas próximas a los accesos públicos (más allá de que exista un riesgo de multa) nos convierte en mejores personas, al tiempo que contribuimos a facilitar la vida de otras que posiblemente -y en su día a día- tengan otras dificultades añadidas a las más frecuentes. (Molina, 2017, p. 36)

\section{El concepto de situación de discapacidad}

En la medida en que sigamos utilizando un sintagma preposicional para tratar de abundar en esta conceptualización sobre la discapacidad, de modo que en nuestro discurso nos refiramos a la persona siempre utilizando la expresión "persona con”, con toda seguridad lo que venga tras la preposición será algo inherente a la propia persona: no es posible otro entendimiento. Por ejemplo, si estuviésemos aguardando nuestro turno para ser atendidos en un banco (o en un hospital, o en la carnicería...) y de repente alguien se acercara y nos dijera que en ese mismo espacio en el que aguardamos hay (también esperando su turno) una persona con peligrosidad, probablemente entraríamos en una situación de alerta con consecuencias imprevisibles (empezaríamos a sospechar de algunos de quienes nos rodean, trataríamos de marcharnos, nos echaríamos mano a nuestras pertenencias...). Sin embargo, cosa diferente sería si quien nos alerta nos hubiese dicho que en esa misma estancia hay una persona "en situación de" peligrosidad, con toda seguridad podría salir el samaritano que muchos llevan dentro (desde esa mirada vocacional de entrega a los demás, de ayuda) y hacer que ese buscar - con la mirada- a la persona vulnerable anunciada pudiera convertirse en una oportunidad para ayudarle a tratar de salir de esa situación de peligrosidad (o a minorarla). Aprecie el lector la interesante diferencia que hay ahora en la construcción semántica; al hablar de "persona en situación de" se hace referencia a algo que, de la misma forma que puede darse (la situación), también podría desaparecer o cambiar (precisamente con la actuación de una persona debidamente preparada para ello (Álvarez et al., 2021). Es ahí, precisamente, donde radica la importancia de este entendimiento: cuando hablamos de la escuela, si decimos que es un niño "con discapacidad" ¿qué estamos queriendo decir a la sociedad? Evidentemente, padres, compañeros e 
-incluso- el resto de niños solo pueden entender la literalidad de nuestras palabras: que es el niño el que tiene la discapacidad (el que la porta, como cualidad adicional propia). Y en ese escenario, el maestro no puede -por menos- que resignarse, ya que ese "con discapacidad" no va a cambiar por más que pueda él esforzarse con su actuación. Sin embargo, y en el mismo contexto y ejemplo, ¿qué estaríamos diciendo si lo que dijésemos fuese un niño "en situación de discapacidad"? Evidentemente el tenor literal de esta construcción nos hace ver que hay un menor en una situación de algo que parece negativo, y con toda certeza es en estas ocasiones en las que ese maestro que llevamos dentro puede hacer acto de presencia consciente (y convencido) de que -con su actuación y proceder- con toda seguridad esa situación podrá modificarse y-tal vez- minorarse (Álvarez et al., 2021).

\section{El concepto de desempeño funcional}

Cuando el desarrollo de la conceptualización de "personas que se encuentran en situación de discapacidad" se une al estudio y entendimiento de los importantísimos aportes de la ONU a través de su última convención de derechos humanos (2006), estamos en mejores condiciones para entender que eso a lo que estamos llamando "situaciones de discapacidad" (y que con la CDPD se asocia al resultado de la interacción entre la sociedad -a través de las barreras que impone- y las capacidades del sujeto al enfrentarse a dicha sociedad) no son sino -por esta misma lógica- situaciones de discriminación en las que la ratio decidendi acaba siendo el desempeño funcional del ser humano. Es decir, que cuando nos encontramos (por poner un ejemplo) con un escenario en el que un joven con síndrome de Down es rechazado en una entrevista de trabajo de teleoperador porque quien le contrataría cree que el candidato no tiene lo que jurídicamente se conoce como capacidad de entender (o porque su empresa no está preparada para esa comunión, etc.), claramente estaríamos ante una situación de discriminación en la que el motivo sería el desempeño funcional (para este caso, un bajo desempeño funcional a nivel intelectual). Es decir, como sabemos las situaciones de discriminación pueden tener diferentes motivos, y dado que la discapacidad es una cuestión de derechos humanos, al hablar de situaciones de discriminación por motivo de discapacidad (para nosotros la semántica adecuada sería "por motivo de desempeño funcional”) la mirada hay que volcarla -precisamente- a que nos encontraríamos ante una situación de discriminación.

Para cualquier capacidad humana (por ejemplo, la capacidad visual), en toda persona existe todo un rango de desarrollo que va desde el máximo desempeño conocido (véase el caso de los tiradores olímpicos) hasta el valor cero de dicha capacidad (que en el caso de este ejemplo sería la ceguera). Tomando este mismo ejemplo, si hablamos de la capacidad de salto lo normal debiera ser entender que, si bien hay personas capaces de saltar 2,45 metros, otras -sin embargo- nunca podrán saltar; esta situación -que efectivamente es la normal- contribuye al desarrollo de esa conceptualización que utilizamos al hablar de desempeño funcional. Cuando hablamos de desempeño funcional en una capacidad específica del ser humano, hacemos referencia-precisa- 
mente- al grado de desempeño que (para esa capacidad y momento vital del sujeto) tiene una persona en particular. La trazabilidad en el desarrollo conceptual de este neologismo lleva a pensar que -por ejemplo-, al hablar de la capacidad para realizar -con autonomía- las tareas vinculadas al aseo personal, lo normal es que en los primeros años de infancia el ser humano muestre un bajo desempeño funcional en esta capacidad, la cual va desarrollándose a lo largo de la vida hasta llegar un punto (la vejez) en el que -generalmente- comienza a decrecer hasta llegar (incluso, en algunos casos) a alcanzar de nuevo el valor cero. Fácil sería imaginar cuál sería el dibujo que adoptaría una gráfica que tratase de representar esta capacidad aludida. Lógicamente, a diferentes capacidades (saltar, respirar, mirar, hablar...) corresponderían distintas gráficas; y cabría hacer gráficas individuales (que serían las que tendrían sentido específico -y privado- para un niño en la escuela), como también colectivas (que permitirían perpetuar esa perversión de la que tanto gustan los amantes de lo homogéneo y los estereotipos, en la medida en que un sujeto se acercase o alejase a un determinado patrón de norma estadística -que no es a lo que aludimos en nuestra reflexión-). Por lo tanto, no es posible hablar de "personas con desempeño funcional" (como sucedía al hablar de "personas con diversidad funcional” versus "personas sin diversidad funcional”) ya que el desempeño funcional es consustancial al ser humano (por analogía a lo que la condición humana es a la persona o lo que el color blanco es a la nieve).

\section{El concepto de persona desde la teoría de los valores}

La cuestión acerca de la dignidad de la persona humana y, por ende, de las personas que se encuentran en situación de discriminación por un bajo desempeño funcional requiere eliminar -desde un principio- todo rastro de ablepsia intelectual. En efecto, la persona con bajo desempeño funcional no puede considerarse nunca como un objeto, como un qué, sino que debe ser exclusivamente concebida como un quién. El (para nosotros) denostado modelo médico de la discapacidad (Dalmeda y Chhabra, 2019), que concibe la misma como una suerte de deficiencia individual que hay que rehabilitar (Palacios y Bariff, 2007, p. 15), se identifica con aquella concepción de la persona entendida como un qué, en contraste con la persona concebida como un quién (más acorde con el modelo de los derechos humanos), que respeta el derecho a la diferencia y patentiza la construcción social de la diversidad funcional a partir de la interacción entre las limitaciones físicas, intelectuales o sensoriales en su encuentro con las barreras sociales creadas por el entorno (Administración, políticas públicas, sociedad...).

Atendiendo a los fundamentos de la conocida teoría de los valores, la pregunta obligada es la siguiente: ¿quién es la persona humana? Siguiendo al pensador alemán Max Scheler (1874-1928), para responder adecuadamente a esta pregunta debemos distinguir entre la noción de persona y la noción de yo; la persona no es un qué, no es un algo objetivable ni susceptible de investigación psicológica, sino un quién perceptible sentimentalmente y susceptible de investigación filosófico-axiológica. La persona humana se identifica con su actus essendi (o existencia) y equivale al acto de ser; 
mientras que el yo designa propiamente aquello que en época medieval era designado como essentia o esencia (Sosein). Para Scheler, persona significa -primordialmenteespíritu (Geist) y ahí es donde radica el fundamento de la dignidad personal: no en la esencia (o en lo común a todo lo humano), sino -precisamente- en aquello que es irreductible al yo (Scheler, 2001, p. 521).

En este orden de cosas, Scheler distingue entre actos y funciones, de manera que mientras que los primeros son de índole espiritual y -por lo tanto- inmateriales y ajenos a la esfera espacio-temporal (comprender, querer, amar, etc.), las segundas (funciones) presuponen un cuerpo y un contorno espacio-temporal. Por eso los actos pertenecen genuinamente a la persona como espíritu, quien ejerce un papel de principio unitario y fundante respecto de actos esencialmente diversos, mientras que las funciones pertenecen a ese ámbito del yo. El espíritu es así concebido como lo que posee la esencia del acto, de la intencionalidad y de la implementación de sentido (Scheler, 2001, p. 518), caracterizado por las notas de actualidad, inobjetivabilidad, intencionalidad y personalidad. Por consiguiente, siendo el acto de ser personal lo distintivo de cada quien y la clave de su identidad, toda objetivación psicológica conduce a una despersonalización que soslaya el sentido de sus actos. La persona, desde la perspectiva de la teoría de los valores, es realizadora de actos intencionales ligados por una unidad de sentido y así, de un modo claro y diáfano, lo expresa Scheler:

De lo dicho se deduce que toda objetivación psicológica es idéntica a la despersonalización; y que la persona es dada siempre como el realizador de actos intencionales que están ligados por la unidad de un sentido. Por consiguiente, nada tiene que ver el ser psíquico con el ser personal. (Scheler, 2001, p. 623)

A su vez, resulta muy fácil apreciar el paralelismo entre el modo de concebir el desempeño funcional desde el modelo médico-rehabilitador y la objetivación y la despersonalización propias del enfoque puramente psicológico. Las personas con bajo desempeño funcional son -ante todo- personas (valga la tautología), de forma que toda referencia a las características físicas o intelectuales que están en la base del concepto de deficiencia no puede hacerse sino desde una perspectiva social. Desde esta óptica, existe otro modelo que se ajusta mejor a la evolución del concepto de discapacidad recogido en los documentos de la OMS, claramente inclinados hacia la concepción del desempeño funcional como una cuestión ajena a cualquier objetivación (más propia del anterior modelo médico): la consideración de la discapacidad como una cuestión de derechos humanos. En efecto, la Clasificación Internacional de la Deficiencia, Discapacidad y Minusvalía (1980) definía la deficiencia como una pérdida o anormalidad funcional; la discapacidad como una restricción de la actividad en el ámbito normal; y la minusvalía como una incapacidad o desventaja en el ejercicio de un determinado rol social según edad, sexo o factores culturales y sociales. Como respuesta a las críticas generalizadas a este modelo (desde el que no se consideraba que la discapacidad pueda derivar directamente de causas sociales), la OMS elaboró la Clasificación Internacional del Funcionamiento, la Discapacidad y la Salud (2001), donde se define la discapacidad como una deficiencia o limitación en la actividad de la 
persona, así como una serie de restricciones a su participación, producto de factores ambientales que generan barreras procedentes del mundo físico, social y actitudinal. Esta última clasificación encuentra su acogida en la ONU con la promulgación -años más tarde- de la CDPD (2006), en cuyo articulado queda debidamente permeado tanto el contenido del neologismo desempeño funcional, como también el modelo de los derechos humanos (sobrepasando -así-al modelo social).

\section{El fundamento amoroso del valor de la persona}

Una vez definida la persona como quién, y afirmada su esencia espiritual, surge la cuestión de determinar cómo es posible conocerla. En este sentido, Scheler diferencia entre la persona y la personalidad siendo -propiamente- esta última la distinción que refleja la oposición medieval entre acto de ser y esencia, y entre espíritu y ser psíquico (respectivamente):

De todo lo que va dicho síguese, sin más, que todo espíritu, necesaria y esencialmente es "personal", y que la idea de un "espíritu impersonal" es "absurda". Mas en modo alguno pertenece a la esencia del espíritu un "yo"; ni tampoco -consiguientemente- una distinción del "yo y el mundo exterior”. Antes -bien- la persona es la forma de existencia única, esencial y necesaria del espíritu. (Scheler, 2001, p. 520)

En suma, si tenemos en cuenta -además- la dimensión bio-psicológica del ser humano, la estructura de la persona resultante se organiza en tres niveles: un primer nivel inferior (de carácter orgánico-sensible), constituido por el cuerpo humano; un segundo nivel (de carácter psicológico) que dirige al orgánico, denominado por Scheler centro vital y en el que radicaría el yo -como conciencia vital responsable de los actos psíquicos-; y un tercer nivel de carácter espiritual, equivalente al acto de ser en el que consiste propiamente la persona, y responsable de los actos espirituales. En definitiva, quedan la persona y sus actos espirituales como algo superior a la conciencia psicológica.

Retomando nuevamente la distinción entre persona y personalidad, Scheler concibe la persona y el yo como niveles del ser humano de donde surgen actos diversos y que son objeto de conocimiento diferenciado: mientras el yo es susceptible de conocimiento objetivo, la persona es inobjetivable y su conocimiento solo puede tener lugar a través de un acto espiritual puro como es el movimiento del amor. La pregunta de obligada respuesta, llegados a este punto, es: ¿cómo se conoce la persona? Scheler responde que, así como la razón conoce objetivamente mediante la formación de ideas o representaciones, el espíritu conoce -directamente- sin la mediación de ideas o razonamientos, a través de una intuición pura (Scheler, 2001, p. 356). Dicha intuición espiritual pura se canaliza a través del acto espiritual más elevado de la persona: el amor. La persona es percibida como tal en su valor absoluto de una forma sentimental, no racional, a través del amor (Scheler, 2001, p. 363). Lo que Scheler defiende en último término es un conocimiento axiológico íntimo de la persona espiritual a 
través del amor. Mas nuevamente surge aquí otra dificultad: ¿cómo se produce dicho conocimiento axiológico a través del amor? La respuesta que nos da Scheler es bien sencilla: a través de la coejecución de los actos de la persona amada (Scheler, 2005, p. 233). Es decir, solo pensando, queriendo y sintiendo con la persona amada puede alcanzarse su existencia real. El amor constituye un movimiento espontáneo de la persona como realidad espiritual orientado hacia el valor -aunque con término en lo valioso en la medida en que no se ama un valor, sino a alguien que es valioso-, y que supone una libre entrega a la realidad del amado frente al poder de la vida impulsiva. El amor posee -además- una significación creadora por cuanto descubre el valor más alto posible de la persona amada como si brotase de sí mismo:

El amor es el movimiento en el que todo objeto concretamente individual que porta valores, llega a los valores más altos posibles para él con arreglo a su determinación ideal; o en el que alcanza su esencia axiológica ideal, la que le es peculiar. (Scheler, 2005, pp. 225-226).

Dietrich Hildebrand (1998), en una línea análoga a la de Scheler, concibió el amor como una respuesta supra-actual al valor (Hildebrand, 1998, p. 49). Para él, los valores son como un rayo, un resplandor del bien conectado de modo plenamente temático a la persona. Es decir ( $y$ en esto coincide con Scheler), los valores deben estar unidos de modo central a la persona. Una hipotética incapacidad de indicar valores concretos que motiven el amor, como sostenía Scheler, apunta (según Hildebrand, 1998) a que la mirada hacia el valor va dirigida a la belleza integral de la persona. La belleza integral de la individualidad amada es inefable: aunque se nutra de un elenco de valores vitales, espirituales y morales, estos no pueden ser descompuestos. Es la individualidad de todo el ser personal la que tiene que aparecernos como excelente y bella para que esa persona despierte el amor. En la medida en que se apreciaran rasgos aislados, faltaría el fundamento específico del amor, es decir, la percepción de la belleza integral de la persona amada:

Se presupone una captación del valor para el surgimiento del amor. Pero el amor nos capacita para una nueva y más profunda captación de valor. Esta última, a su vez, fundamenta un nuevo y más profundo amor, y este -por su parte- una nueva y más profunda captación de valor. (Hildebrand, 1998, p. 55)

En conclusión, desde la perspectiva de la teoría de los valores resulta palmario el hecho de que la dignidad de la persona y su íntimo valor no es producto de un elenco de valores individuales ni de la suma de cualidades o talentos particulares. Muy al contrario, el valor último de la persona -su dignidad esencial- no es resultado de la existencia de determinadas condiciones, ni tan siquiera se trata de una noción o elemento conceptualizable racionalmente. La dignidad absoluta de la persona humana no es un concepto creado por la razón, sino un valor descubierto por la capacidad estimativa humana y dado en el sentir puro. La dignidad humana (su valor más profundo) es algo que se siente; sin perjuicio de la posibilidad de su conceptualización posterior, la dignidad humana se experimenta en el ámbito del sentimiento de humanidad hacia todo 
igual, al margen de sus características, talentos o cualidades particulares que acaban siendo objeto no tanto de sentimiento como de pensamiento y conceptualización. ¿Significa eso que la dignidad de la persona humana incluiría (como no podía ser de otra manera) la de las personas con menor desempeño funcional y que su percepción supondría introducir un elemento irracional? De ningún modo; podría decirse que el amor que está en la base de la percepción emocional del valor es la forma más pura de inteligencia que existe. Lo que sucede es que la posterior conceptualización del fenómeno no da cuenta del verdadero origen del valor, más allá del simple pensamiento racional. Más bien es el pensamiento racional quien bebe de la fuente del valor descubierto en el movimiento amoroso de la mente humana. Debemos -por tanto- acudir a este concepto contemporáneo de persona y dignidad para ofrecer una base teórica a la dignidad de todas las personas, incluidas, cómo no, las personas que se encuentran en situación de discriminación por su desempeño funcional; más aún cuando esta concepción filosófica resulta más acorde con la Convención Internacional de la ONU sobre los Derechos de las Personas que se encuentran en situación de Discapacidad, como veremos a continuación, en la medida en la que va más allá de las diferencias físicas, mentales, intelectuales o sensoriales y se focaliza en la capacidad de amar y de ser amada de toda persona, fundamento último de la naturaleza humana.

8. La Convención Internacional de Naciones Unidas sobre los Derechos de las Personas en situación de Discapacidad: implicaciones en el ámbito de la dignidad

Con precedentes en los tratados generales sobre derechos humanos de la Organización de Naciones Unidas ${ }^{1}$, la diversidad funcional se planteó como una cuestión de derechos humanos - con carácter específico- a raíz de que la Comisión de Derechos Humanos de la ONU instase a los órganos de vigilancia encargados del cumplimiento de los tratados generalistas precedentes a que tuviesen en cuenta los derechos de las personas que se encuentran en situación de discriminación por su desempeño funcional. La constatación de la falta de un instrumento específico que, a diferencia de lo sucedido con otros colectivos considerados de especial protección (como las mujeres o los niños), contemplase con un carácter particular a las personas con bajo desempeño funcional motivó la elaboración y aprobación de la Convención Internacional de la ONU sobre los Derechos de las Personas en situación de Discapacidad (CDPD) y su posterior Protocolo Facultativo, plenamente en vigor en España desde 3 de mayo de 2008.

Las consecuencias de la aparición de la CDPD ya fueron puestas de relieve por diferentes autores (Palacios y Bariff, 2007; Molina, 2017; Molina, 2020), destacando

1 Son los siguientes: Convención sobre la eliminación de todas las formas de discriminación racial (1963); Pacto internacional de derechos económicos, sociales y culturales (1966); Pacto internacional de derechos civiles y políticos (1966); Convención sobre la eliminación de todas las formas de discriminación contra la mujer (1982); Convención contra la Tortura y Otros Tratos o Penas Crueles, Inhumanos o Degradantes (1984); Convención sobre los derechos del niño (1989). 
-fundamentalmente- tanto la visibilidad del colectivo de personas con menor desempeño funcional dentro del sistema de protección de Derechos Humanos de la ONU (en el ámbito de los valores y en el ámbito del derecho), como también la asunción decidida de que todos somos diversos funcionalmente como una cuestión de derechos humanos, dotando -por primera vez- a dicho colectivo de una herramienta jurídica explícita y concreta para hacer valer sus derechos humanos.

En este sentido, la apuesta de la Convención es muy decidida: su objeto es la protección contra la discriminación y en pro del efectivo ejercicio de los derechos de las personas que se encuentran en situación de discriminación por su desempeño funcional (art. ${ }^{\circ}$ 1), estableciendo expresamente el principio de no discriminación junto con el ejercicio de derechos sustantivos explícitamente regulados, y siempre con el fin de promover, proteger y asegurar el goce pleno y en condiciones de igualdad de todos los derechos humanos de las personas en situación de discapacidad. Destaca-ademáscomo uno de sus principales objetivos promover el respeto a la dignidad inherente de las personas con bajo desempeño funcional, así como adaptar las normas de los tratados internacionales al contexto de la diversidad funcional a través de mecanismos de no discriminación e igualdad de oportunidades. En el contexto de la Convención, el concepto de discapacidad que se desprende a la luz del art. ${ }^{\circ} 1$, así como del espíritu manifestado en el preámbulo de la misma, refleja de un modo implícito y -a la vezdiáfano: el modelo de los derechos humanos. Bajo este paradigma, la discapacidad se concibe como un concepto en evolución, resultado de la interacción de dos factores: por un lado, las personas con deficiencias o limitaciones individuales (físicas, mentales, intelectuales o sensoriales a largo plazo); y, por otro lado, de la aparición de barreras derivadas de la actitud y del entorno social, resultando así la discapacidad de la interacción entre ambos elementos.

Desde un punto de vista filosófico y jurídico, el modelo de los derechos humanos (desde la consideración del fenómeno como una cuestión social y de derecho) se traduce en el reconocimiento de la personalidad jurídica de quienes tienen bajo desempeño funcional (art. ${ }^{\circ} 12$ ), así como en la implementación de medidas de apoyo en orden a asegurar la toma de decisiones. Dicha perspectiva se aprecia con claridad meridiana en los principios de la Convención (art. ${ }^{\circ} 3$ ), considerados como auténtico puente entre el ámbito jurídico y el ámbito ético-filosófico de los derechos humanos, garantizando el respeto de su dignidad inherente (como personas), su autonomía individual, la libertad de tomar las propias decisiones, la independencia, el principio de no discriminación, el fomento de su participación e inclusión efectivas en la sociedad, el respeto por la diferencia (con la consiguiente aceptación del colectivo de personas con bajo desempeño funcional como parte de la diversidad y condición humanas), el principio de igualdad de oportunidades, la accesibilidad, la igualdad entre el hombre y la mujer, así como el respeto a la evolución de las facultades de los niños y niñas en situación de discapacidad y de su derecho a preservar su identidad.

Desde un punto de vista estrictamente filosófico, la dignidad humana se concibe como un atributo esencial de la persona a partir de la ilustración: "Las cosas tienen precio, las personas tienen valor” (Kant, 2003, p. 74). Así, con Kant, la persona es un sujeto, un "fin en sí misma” en virtud de su autonomía y libertad y con base en una 
racionalidad expresada desde un punto de vista práctico por el imperativo categórico: "Obra de tal modo que uses la humanidad, tanto en tu persona como en la persona de cualquier otro, siempre como un fin y nunca solamente como un medio" (Kant, 2003, p. 67).

Sin embargo, la aparición de la sociedad de consumo y la asunción de una ética utilitarista (Bentham, 1789; Mill, 1873) conlleva la percepción de las situaciones de discapacidad como una limitación o minusvalía que menoscaba el valor útil de la persona, una concepción a todas luces contraria a la dignidad esencial de la persona y al concepto más genuinamente ilustrado. Lo cierto es que la dignidad constituye la base filosófica de los derechos humanos; no en vano, pueden definirse los derechos humanos como concreciones de la dignidad humana. Así pues, la dignidad (y no la utilidad) es el concepto clave que sirve como piedra angular sobre la que descansa la consideración social de las personas con bajo desempeño funcional, allende consideraciones pragmáticas o utilitaristas. Ahora bien, aparecen algunos problemas relativos al concepto moderno de dignidad basado -a su vez- en el concepto ilustrado de razón. La idea ilustrada de sujeto como aquel con capacidad de razonar, sentir y comunicarse no es completamente coherente ni suficiente para dar cuenta de la dignidad humana que -indudablemente- posee la persona con bajo desempeño funcional, incluso cuando recaiga sobre dichas facultades. Es preciso, por consiguiente, acudir a un concepto humanista mucho más comprensivo e inclusivo como es el de naturaleza humana, base de la dignidad, y que va más allá -incluso- de las capacidades actualizadas de la persona.

Ni que decir tiene que la dignidad esencial de la persona es el fundamento del valor ético absoluto de todo ser humano, sin excepción, condición inherente a la naturaleza humana. La persona es definida por Max Scheler como el "valor de los valores" (Scheler, 2001, p. 658). Contrasta -así- la concepción utilitarista de la persona como mero medio, frente al valor absoluto de la persona como valor de los valores o como fin en sí misma. Resulta palmario que la persona posee un valor absoluto, una dignidad, al margen de su aporte social en términos puramente económico-utilitaristas. La naturaleza humana es exactamente la misma en las personas con mayor y menor desempeño funcional en la medida en que las limitaciones biológicas no afectan a la consideración ética de la persona, y el componente biológico de la diversidad funcional es estrictamente accidental. En cambio, el componente bioético de la diversidad funcional es sustancial: las personas con bajo desempeño funcional no pierden su carácter humano por la imposibilidad de ejercitar determinadas facultades de carácter físico o intelectual. En realidad, el modelo de los derechos humanos nos enseña que las situaciones de discapacidad son, en verdad, un constructo social y no algo esencial ni -por supuesto- basado en la naturaleza humana. Es por este motivo que es preferible acudir a los conceptos de naturaleza humana y de valor para fundamentar la dignidad de las personas con bajo desempeño funcional, por resultar mucho más profundo y esencial que el de racionalidad (que está en la base de la concepción ilustrada de sujeto). El colectivo de personas que se encuentran en situación de discapacidad nos ofrece -así- un modelo perfecto en el que fundamentar (sin reservas) la dignidad de todas las personas. 
En conclusión, de la dignidad sustancial e innata basada en el valor de todo ser humano, se desprende la igualdad esencial de todas las personas, potencialmente idéntica en todas ellas, al margen de su condición de personas con mayor o menor desempeño funcional. La condición humana de todas las personas implica que todas son iguales en cuanto a su valor, al margen de diferencias físicas, mentales, intelectuales o sensoriales. En cualquier escenario, en ningún caso puede quedar afectada la capacidad de amar y de ser amada de la persona, fundamento último del valor y de la condición humana. La dignidad de las personas con bajo desempeño funcional se traduce así en el reconocimiento de su autonomía y libertad, y de su derecho a vivir de forma independiente y a ser incluidas en la comunidad (art. $\left.{ }^{\circ} 19\right)$, de modo que el Estado debe adoptar medidas efectivas y pertinentes para facilitar el pleno goce de este derecho, así como su inclusión y participación en la vida social: como indicaba el eslogan de aquel movimiento de vida independiente, "nada sobre nosotros sin nosotros".

\section{Referencias bibliográficas}

Álvarez, J. M., Díaz, Y. y Molina, J. (2021). El código Cuomo. Las fábulas de María: una niña a la que no le gustaba la escuela. Dykinson.

Bentham, J. (1789). An introduction to the principles of morals and legislation. Batoche Books. Braslavsky, C. (2006). Diez factores para una educación de calidad para todos en el siglo XXI. REICE: Revista Electrónica Iberoamericana sobre Calidad, Eficacia y Cambio en Educación, 4(2), 84-101.

Campoy, I. (2017). La construcción de un modelo de derechos humanos para los niños, con o sin discapacidad. Revista de Filosofía del Derecho y Derechos Humanos, 37, 131-165.

Dalmeda, M. E. P. y ChHabra, G. (2019). Modelos teóricos de discapacidad: un seguimiento del desarrollo histórico del concepto de discapacidad en las últimas cinco décadas. Revista Española de Discapacidad (REDIS), 7(1), 7-27.

Foschiani, G. (2017). El rol del comité de los derechos de las personas con discapacidad. El derecho a la educación inclusiva y de calidad. Ramón Areces.

Hildebrand, D. (1998). La esencia del amor. EUNSA

Hildebrand, D. (2006). Moralidad y conocimiento ético de los valores. Cristiandad.

Kant, I. (1989). La metafísica de las costumbres. Tecnos.

KANT, I. (2002). Crítica de la razón práctica. Alianza Editorial.

KANT, I. (2003). Fundamentación de la metafísica de las costumbres. Encuentro.

LÓPEZ, J. L. (2019). La conceptualización de la discapacidad a través de la historia. Una mirada a través de la evolución normativa. Revista de la Facultad de Derecho de México, 69(273), $835-856$.

Mill, J. (1873). Last stage of education and first of self-education. P. F. Collier \& Sons

Molina, J. (2017). La discapacidad empieza en tu mirada. Las situaciones de discriminación por motivo de diversidad funcional: escenario jurídico, social y educativo. Delta Publicaciones.

Molina, J. (2020). El derecho a la educación inclusiva: un engaño revestido de verdad. En M. Fernández, D. Heras y J. A. Gómez (Coords.), Ampliando borizontes en educación inclusiva (pp. 159-167). Universidad de Burgos.

ONU. (1960). Convención relativa a la Lucha contra las Discriminaciones en la esfera de la Enseñanza. ONU. 
ONU. (1993). Normas Uniformes sobre la Igualdad de Oportunidades para las Personas con Discapacidad. ONU.

ONU. (2006). Convención sobre los Derechos de las Personas con Discapacidad y Protocolo Facultativo. ONU.

ONU. (2008). Conferencia internacional de educación. La educación inclusiva: el camino hacia el futuro. ONU.

Palacios, A. y BARIFFi, F. (2007). La discapacidad como una cuestión de derechos humanos. CERMI.

Román, Á. D. (2011). La huella de San Agustín en la ética de los valores de Scheler. Tesis doctoral. Universidad de Murcia.

Román, Á. D. (2012). Valor y educación del amor según Max Scheler y San Agustín de Hipona. Studia Gilsoniana, 1, 75-89.

Román, Á. D. (2013). El orden del amor: San Agustín y la ética de los valores de Scheler. Augustinus, 58, 119-161.

SCHELER, M. (1996). Ordo amoris. Caparrós Editores.

SCHELER, M. (2001). Ética: nuevo ensayo de fundamentación de un personalismo ético. Caparrós Editores.

Scheler, M. (2005). Esencia y formas de la simpatía. Ediciones Sígueme.

Scheler, M. (2010). Amor y conocimiento. Palabra.

Stiker, H. J. (2017). Cuerpos perdidos, cuerpos reconquistados. Las grandes secuencias de la historia de la discapacidad. Boletín Onteaiken, 23, 1-9.

Teresinha, G. (1998). Los valores y la moral en la escuela. Educação and Sociedade, 19(62), 64-80. 